\title{
Estrutura física das unidades de endoscopia: a realidade do reprocessamento
}

\author{
The physical structure of endoscopy units: the reality of reprocessing
}

Estructura física de las unidades de endoscopía: la realidad del reprocesamiento

\begin{abstract}
Jackeline Maciel Barbosa ${ }^{1}$, Adenícia Custódia Silva e Souza ${ }^{2}$, Luana Cássia Miranda Ribeiroº ${ }^{3}$ Heliny Carneiro Cunha Neves ${ }^{4}$, Francine Vieira Pires ${ }^{5}$, Anaclara Ferreira Veiga Tipple ${ }^{6}$
\end{abstract}

\section{RESUMO}

Pesquisa descritiva realizada nas unidades de Endoscopia Digestiva Alta em 2007, que objetivou analisar a estrutura física da área destinada ao reprocessamento dos endoscópios no município de Goiânia-GO. Os dados foram obtidos e registrados em um check-list mediante observação direta da estrutura física e dos recursos materiais do local de reprocessamento dos endoscópios. Constatou-se que a maioria $(95,0 \%)$ das unidades de endoscopia possui um fluxo de reprocessamento inadequado. Deficiências estruturais foram observadas nos locais de reprocessamento, tais como tipo de revestimento, piso, forro contínuo, presença de pia para higienização das mãos, ausência de exaustor e ponto de ar comprimido. Concluiu-se que as deficiências estruturais identificadas potencializam o risco químico e biológico tanto para o profissional, quanto para o usuário e ainda podem comprometer o reprocessamento adequado dos endoscópios.

Descritores: Arquitetura de instituições de saúde; Endoscopia; Glutaraldeído; Desinfecção.

\section{ABSTRACT}

This descriptive study was performed at several digestive endoscopy units in 2007, with the objective to analyze the physical structure of the area devoted to endoscope reprocessing at units located in Goiânia-GO. The data were obtained through direct observation of the physical structure and the material resources of the endoscope reprocessing area and recording these characteristics on a checklist. Most (95.0\%) endoscopy units have an inadequate reprocessing flow. It was observed that the reprocessing areas had structural deficiencies in terms of the type of wall covering, floor tiles, continuous ceilings, the presence of a sink for hand washing, no exhaust fans and compressed air outlets. In conclusion, the identified structural deficiencies increase the chemical and biological risk for professionals and clients, and may also compromise the adequacy of endoscope reprocessing.

Descriptors: Facility Design and Construction; Endoscopy; Glutaral; Disinfection.

\section{RESUMEN}

Investigación descriptiva realizada en unidades de Endoscopía Digestiva Alta en 2007, objetivó analizar la estructura física del área destinada al reprocesamiento de endoscopios en unidades de endoscopía del municipio de Goiânia-GO. Datos obtenidos mediante observación directa de estructura física y recursos materiales del local de reprocesamiento de endoscopios y registrados en checklist. La mayoría $(95,0 \%)$ de unidades endoscópicas posee un flujo de reprocesamiento inadecuado. Fueron observadas deficiencias estructurales en los locales, como tipo de revestimiento, techado, piso, revestimiento continuo, presencia de pileta para higienización de manos, ausencia de exhaustor y compresor de aire. Se concluye en que las deficiencias estructurales verificadas potencian riesgos químicos y biológicos para el profesional y el paciente, y puede también comprometer el reprocesamiento adecuado de los endoscopios.

Descriptores: Arquitectura y Construcción de Instituciones de Salud; Endoscopía; Glutaral; Desinfección.

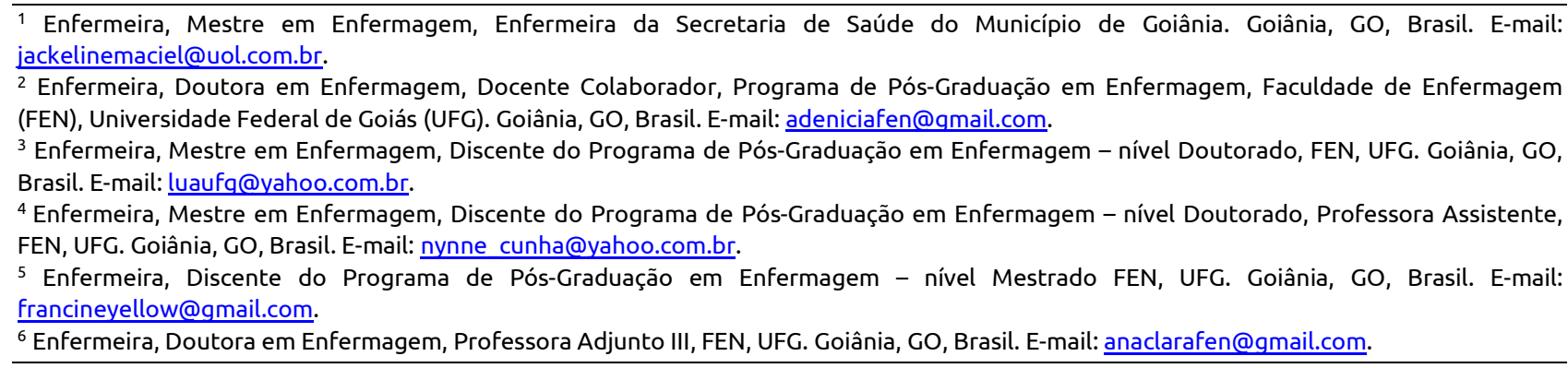




\section{INTRODUÇÃO}

O desenvolvimento tecnológico ocorrido nas últimas décadas impulsionou as atividades desenvolvidas nas unidades de endoscopia de forma vertiginosa, colocando-a como um setor de vital importância para o diagnóstico e a terapêutica, dada a magnitude do trabalho ali desenvolvido.

A unidade de endoscopia é um setor composto de várias áreas, nas quais são realizados procedimentos endoscópicos, em condições de segurança, para os pacientes e equipe multiprofissional(1). $O$ seu planejamento deve ser elaborado, de acordo com as bases normativas do Ministério da Saúde ${ }^{(2-3)}$.

O Regulamento Técnico para Serviços de Endoscopia Digestiva e Respiratória recomenda a observância da RDC/ANVISA - n 50, de 21 de fevereiro de 2002, e no item 6.2.1 informa que a infra-estrutura deve ser adequada às operações desenvolvidas, para assegurar a qualidade dos procedimentos(2).

A área física deve ser planejada de acordo com o número de atendimentos previstos (ambulatorial ou unidade inserida em ambiente hospitalar), tipo de procedimento realizado, quantidade de profissionais envolvidos, fluxo do artigo para o reprocessamento e a tecnologia utilizada (3).

O reprocessamento de endoscópios envolve três fases: etapa pré-desinfecção que engloba a pré-lavagem, limpeza, enxágue e secagem; a etapa desinfecção que é a imersão no glutaraldeído e a pós desinfecção que abrange o enxágue, secagem e estocagem ${ }^{(1,4)}$. São muitos os fatores determinantes para o sucesso desse reprocessamento dos endoscópios, entre eles a estrutura física da unidade de endoscopia que deve oferecer condições, para a execução deste procedimento.

Contudo, a prática cotidiana mostra que os serviços de endoscopia não atendem às recomendações estabelecidas pelos órgãos normativos, tanto no que se refere ao atendimento direto ao usuário, quanto aos aspectos relacionados à estrutura física da área de reprocessamento dos artigos. Vale ressaltar que as diretrizes do Ministério da Saúde quanto ao regulamento técnico para funcionamento de um serviço de endoscopia é recente no país, a partir de $2002^{(2-3)}$.

A inobservância das normas mínimas requeridas para a estrutura e funcionamento da área de reprocessamento, interfere diretamente na qualidade e segurança dos equipamentos disponibilizados para a realização dos exames endoscópicos e, consequentemente, na qualidade do atendimento.

Conhecer a estrutura da área física destinada ao reprocessamento de artigos nos serviços de endoscopia é uma etapa importante, pois contribui para o planejamento de uma estrutura adequada, que contemple os parâmetros necessários para garantir uma qualidade e um reprocessamento seguro ao usuário, bem como minimizar os riscos ocupacionais existentes no ambiente de trabalho.

Assim, este estudo teve o objetivo de analisar a estrutura física da área destinada ao reprocessamento de endoscópios, em serviços de Endoscopia Digestiva Alta (EDA) no município de Goiânia-GO.

\section{METODOLOGIA}

Pesquisa exploratória, descritiva desenvolvida em hospitais e clínicas que realizavam Endoscopia Digestiva Alta (EDA) em Goiânia/GO. A relação dos Hospitais e Clínicas foi cedida pela Divisão de Controle de Infecção nos Estabelecimentos de Saúde de Goiânia - DPCISS, sendo identificados no primeiro semestre de 2007, 62 serviços de EDA.

Fizeram parte do estudo as instituições de EDA que realizam o reprocessamento dos endoscópios pelo uso do glutaraldeído, e consentiram em participar.

Os dados foram obtidos, no período de maio a julho de 2007, por meio de observação direta da estrutura física e recursos materiais do local utilizado para o reprocessamento dos endoscópios e registrados em um check-list, previamente formulado com questões fechadas, elaboradas com base nas recomendações sanitárias oficiais(2-3) e que foi validado por três pesquisadores especialistas na temática.

O banco de dados foi estruturado e processado no programa Statistical Package for the Social Sciences (SPSS) versão 16.0. Foi utilizada a estatística descritiva e os dados foram apresentados em tabelas.

O projeto foi autorizado pelo responsável do serviço de endoscopia das instituições participantes e aprovado pelo Comitê de Ética em Pesquisa Médica Humana e Animal (CEPMHA) do Hospital das Clínicas da Universidade Federal de Goiás sob protocolo $n^{\circ}$ 064/07. 


\section{RESULTADOS}

Todos os serviços de EDA em funcionamento em Goiânia no ano de 2007 foram contactados, 20 (32,3\%) aceitaram participar do estudo, destes, quatro (20,0\%) eram instituições públicas e 16 (80,0\%) privadas. Foram realizadas observações referentes à estrutura física, sendo uma em cada unidade de endoscopia.

Em apenas um (5,0\%) serviço o local destinado ao reprocessamento dos endoscópios era exclusivo e que, em tamanho, era apropriado para comportar todas as etapas do reprocessamento. Nas demais unidades, 19 (95,0\%), essa área era comum para a realização do exame de EDA e o reprocessamento do endoscópio.
A Tabela 1 mostra que em quatro instituições $(20,0 \%)$ havia mais de uma sala para exames, destas, apenas uma $(5,0 \%)$ possuía local exclusivo para o reprocessamento dos endoscópios, as outras três não cumpriam a legislação vigente no país. Em 16 (80,0\%), o reprocessamento era realizado no mesmo local do exame.

O tipo de piso predominante foi o de cerâmica. No teto, o forro contínuo esteve presente em sua maioria $(n=11 ; 55,0 \%)$. A pia para a higienização das mãos não foi observada no local de exame em 13 (65,0\%) unidades de endoscopia e constatou-se, também, a ausência de álcool gel.

Tabela 1: Caracterização da estrutura física das áreas destinadas ao reprocessamento dos endoscópios ( $n=20)$ do município de Goiânia. Goiânia, GO, 2007.

\begin{tabular}{lcc}
\hline Estrutura & $\mathbf{n}$ & $\%$ \\
\hline Área de sala comum & 16 & 80,0 \\
$\quad$ Atende a legislação vigente & 20,0 \\
$\quad$ Não atende a legislação vigente & 04 & \\
Piso & 10,0 \\
$\quad$ Cerâmica & 05 & 25,0 \\
Granitina & 15,0 \\
Vinílico & 03 & 10,0 \\
Granito & 02 & \\
Parede & 11 & 55,0 \\
$\quad$ Tinta epóxi & 09 \\
$\quad$ Tinta óleo & 45,0 \\
Teto & & \\
$\quad$ Forro contínuo & 11 & 55,0 \\
$\quad$ Falso removível & 09 & 45,0 \\
\hline
\end{tabular}

Das unidades investigadas, apenas duas (10\%) dispunha de vestiário para os trabalhadores. No que se refere à pia para higienização das mãos, a maioria dos serviços 13 (65\%) não dispunha desse local e os demais ( $n=7 ; 35 \%)$ possuíam pia apenas no local onde era realizado o exame.

Na única unidade que possuía fluxo adequado, a pia para limpeza e reprocessamento era de granito, provida de ar comprimido e vaso sanitário para desprezar as secreções de aspiração. O acesso era restrito aos trabalhadores que executavam as atividades nas áreas de expurgo e preparo. O expurgo apresentava ventilação natural por meio de uma janela. A área de desinfecção possuía bancada de granito, pia com torneira e ponto com ar comprimido, não possuía janelas ou ar condicionado. Havia um exaustor, que não estava ligado durante o período de observação.

Com base nos 19 (95,0\%) serviços nos quais o reprocessamento era realizado no local do exame, a Tabela 2 mostra as características estruturais dessas unidades.

Observou-se que 15 (78,9\%) unidades possuíam pia com bancada, $13(68,4 \%)$ possuíam ar condicionado, apenas cinco $(26,4 \%)$ com ponto de ar comprimido, e em $15(78,9 \%)$ não haviam exaustores e dentre as quatro que possuíam, apenas um estava ligado no momento da realização da coleta.

Em 19 (95,0\%) dos serviços, o reprocessamento é realizado no local do exame. A Tabela 2 mostra as características estruturais dessas unidades, onde o reprocessamento dos endoscópios foi realizado. 
Tabela 2: Distribuição das características físicas e/ou estruturais dos serviços de endoscopia digestiva alta que compartilham a área de exame e reprocessamento (n=19) do município de Goiânia. Goiânia, GO, 2007.

\begin{tabular}{|c|c|c|}
\hline Características & $n$ & $\%$ \\
\hline \multicolumn{3}{|l|}{ Pia com bancada } \\
\hline Sim & 15 & 78,9 \\
\hline Não & 04 & 21,1 \\
\hline \multicolumn{3}{|l|}{ Material da bancada } \\
\hline Inox & 12 & 63,1 \\
\hline Ausência de bancada & 04 & 21,1 \\
\hline Granito & 03 & 15,8 \\
\hline \multicolumn{3}{|l|}{ Ar condicionado } \\
\hline Sim & 13 & 68,4 \\
\hline Não & 06 & 31,6 \\
\hline \multicolumn{3}{|l|}{ Tipo de ar condicionado } \\
\hline Tipo janela & 13 & 68,4 \\
\hline Ausência de ar condicionado & 06 & 31,6 \\
\hline \multicolumn{3}{|l|}{ Janelas } \\
\hline Não & 10 & 52,6 \\
\hline Sim & 09 & 47,4 \\
\hline \multicolumn{3}{|l|}{ Exaustor } \\
\hline Não & 15 & 78,9 \\
\hline Sim & 04 & 21,1 \\
\hline \multicolumn{3}{|l|}{ Ar comprimido } \\
\hline Não & 14 & 73,6 \\
\hline Sim & 05 & 26,4 \\
\hline \multicolumn{3}{|c|}{ Local que despreza as secreções do frasco de aspiração } \\
\hline Pia utilizada para limpeza do endoscópio & 08 & 42,1 \\
\hline Vaso sanitário do banheiro & 08 & 42,1 \\
\hline Pia exclusiva para este fim & 03 & 15,8 \\
\hline
\end{tabular}

Ao se considerar o total de serviços incluídos no estudo ( $n=20)$, em cinco $(25,0 \%)$ não havia armários para armazenamento dos endoscópios, após o reprocessamento. Estes eram assim armazenados: um (5,0\%) o suporte do próprio aparelho endoscópico, em dois $(10,0 \%)$ suportes de madeira fixados na parede e em dois $(10,0 \%)$ nas malas de transporte dos endoscópios. Quanto ao armazenamento dos endoscópios, em 15 (75,0\%) unidades eram armazenados em armários fechados, nas demais ( $n=5 ; 25,0 \%$ ) os endoscópios eram expostos pendurados na parede ou guardados em maletas. Nos serviços que armazenavam em armários, o material envolvido ега madeira em 14 (70\%) estabelecimentos, sendo 11 (55\%) revestidos de fórmica, destes, sete (35\%) dispunham de válvula de aeração e (20\%) não. Três (15\%) armários não possuíam revestimento e um $(5,0 \%)$ era de metal.

\section{DISCUSSÃO}

Os endoscópios devem ser reprocessados antes de um próximo uso, estando em condições seguras e livres de microrganismos viáveis minimizando o risco de iatrogenias infecciosas(5-6). Garantir a segurança do reprocessamento dos endoscópios é uma importante medida preventiva para as infecções associadas aos cuidados em saúde. Porém, para a eficácia da desinfecção é necessário o conhecimento, a execução adequada de cada fase e possuir uma estrutura física adequada e planejada para o reprocessamento ${ }^{(3,5,7)}$.

Das 20 unidades de endoscopia participantes da pesquisa, quatro possuíam mais de uma sala para exame, e destas, apenas uma possuía área específica destinada ao reprocessamento dos endoscópios que poderá ocorrer na sala de exames, caso essa sala seja única. Se houver mais de uma sala de exame o reprocessamento deverá ser realizado em um local exclusivo para este fim. A unidade de endoscopia que possui mais de uma sala para a realização de exames deve possuir local exclusivo e planejado para o reprocessamento dos endoscópios, de modo que todas as etapas operacionais do 
reprocessamento sejam executadas, garantindo assim um fluxo adequado ${ }^{(3)}$.

Em ambas as condições a área de reprocessamento deverá ser separada em contaminada e limpa, permitindo o estabelecimento de um fluxo contínuo de material, a fim de se evitar o cruzamento de materiais sujos com os limpos(1,5,7). A área contaminada é destinada à realização das etapas de limpeza, enxágue e secagem, tornando os endoscópios seguros, para o manuseio posterior e desinfecção. Na área limpa, são executados os procedimentos de desinfecção, enxágue e secagem do artigo, e em seguida encaminhado para uso ou local de armazenamento(1).

A maioria das unidades de endoscopia possuía área maior que a mínima exigida, que é de $12,0 \mathrm{~m}^{2}$ para área comum, onde são realizados o procedimento de endoscopia, a limpeza e desinfecção do endoscópio. Рara unidades que possuem mais de uma sala para exames com espaços específicos para limpeza e desinfecção dos endoscópios, a área do local de exame deverá ser de 9,0 metros quadrados(3). Outros países recomendam que 0 reprocessamento dos endoscópios deve ser realizado em área designada para esta função e separada do local onde os procedimentos endoscópicos são realizados ${ }^{(8-9)}$.

A única unidade em que havia área distinta, para o reprocessamento dos endoscópios, possuía um fluxo adequado, não permitindo o cruzamento de material não-reprocessado com os materiais reprocessados. Nas demais unidades a área destinada a realização de exame e reprocessamento do endoscópio, apesar de atender ao tamanho recomendado pela $\operatorname{RDC} n^{\circ} 50^{(3)}$ não dispunha de fluxo adequado, para o reprocessamento.

Em relação ao piso, o ideal, em estabelecimentos de saúde, é o uso de pisos contínuos, pois ranhuras e rejuntes possibilitam a agregação de maior sujidade e dificulta a limpeza ${ }^{(5)}$.

As unidades que possuem o piso de granitina são consideradas ideais por não apresentarem rejuntes e serem resistentes a frequentes limpezas e ao uso de desinfetantes $^{(10)}$.

Outro problema evidenciado foi o rodapé dessas unidades, pois a união deste com a parede não estava alinhado e nem abaulado, o que permite a deposição de sujidade, dificultando a limpeza. O recomendado é que as paredes sejam lisas, planas, côncavas ou abauladas sem saliências, cantos e/ou quinas. O material de revestimento deverá ser lavável, durável e de cor suave, para permitir a reverberação da luz ${ }^{(5)}$.

Em 11 (55,0\%) unidades, o revestimento das paredes é considerado adequado, pois as pinturas são feitas com tintas, a base de epóxi, destinadas a áreas molhadas, resistentes à lavagem e ao uso de desinfetantes( ${ }^{(3)}$.

Um aspecto importante a considerar é a utilização de forros falsos removíveis em algumas unidades de endoscopia, sendo estes permitidos nas áreas semicríticas, de acordo com a norma sanitária brasileira ${ }^{(3)}$. Entretanto, devem ser resistentes aos processos de limpeza, descontaminação e desinfecção, estabelecida conforme determina o manual de processamento de artigos e superfícies nos estabelecimentos de saúde(11-12).

Contudo, alguns materiais de forros falsos removíveis, observados nestes serviços de endoscopia, não são passíveis destes processos, devido à impossibilidade de limpeza (gesso, madeira e isopor), e ainda a presença de frestas e saliências no forro de PVC.

A maioria das unidades não apresentava local específico para higienização das mãos. Dados semelhantes foram encontrados por outros autores ${ }^{(13)}$, em hospitais de Goiânia, e em pesquisa ${ }^{(14)}$ em hospitais no Estado de Goiás, na estrutura física do Centro de Material e Esterilização (CME). Questiona-se: como higienizar as mãos, nas unidades de endoscopia, se a maioria não possuía pia exclusiva para higienização das mãos?

No projeto arquitetônico, deve constar pia para a higienização das mãos, em número suficiente, e de uso exclusivo, com dimensionamento apropriado, localizadas em pontos estratégicos, a fim de evitar a recontaminação das mãos, bem como dos artigos, oferecendo segurança aos pacientes e profissionais da saúde ${ }^{(15)}$

A $\quad$ RDC $\quad n^{\circ} \quad 50 \quad$ recomenda vestiários/banheiros/sanitários de barreira nos compartimentos destinados à realização de procedimentos assépticos em área crítica ${ }^{(3)}$. Os serviços de endoscopia, considerados áreas semicríticas devem ter vestiários/banheiros/sanitários para a paramentação e uso exclusivo dos profissionais, porém somente dois $(10,0 \%)$ serviços observados disponibilizavam estes espaços para o trabalhador.

A área de reprocessamento deve ser planejada e contemplar: espaço para todas as etapas de limpeza e 
desinfecção; ventilação; iluminação; superfícies de trabalho; rede elétrica, de água e ar comprimido adequados; pia para higienização de mãos e olhos; fonte de luz para a realização do teste de vazamento, antes do processo de desinfecção; vaso sanitário exclusivo, para desprezar as secreções do frasco de aspiração utilizado no procedimento endoscópico e local para estocagem $^{(1,7)}$.

Na estrutura física do local de reprocessamento, foram constatadas inconformidades. A maioria não possuía exaustores e pontos com ar comprimido para a secagem dos endoscópios. Em 16 (84,2\%) unidades as secreções eram desprezadas no mesmo local de limpeza dos endoscópios ou no vaso sanitário do banheiro. O indicado seria a instalação de um vaso sanitário exclusivamente para este fim, contudo isto só é possível em unidades que possuem local específico para o reprocessamento dos endoscópios, com estrutura

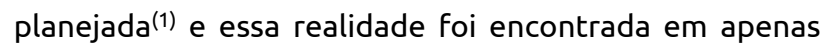
uma unidade no presente estudo.

A ausência de local exclusivo para desprezar as secreções possibilita a contaminação cruzada e, como consequência propicia a recontaminação do endoscópio durante a limpeza manual e/ou enxágue.

Devido ao uso de desinfetante químico tóxico (glutaraldeído) a ventilação da área do reprocessamento deve ser cuidadosamente planejada, inclusive com uso de exaustores.

Observa-se que em quatro $(21,1 \%)$ serviços haviam exaustores e destes, apenas um (5,3\%) estava ligado no momento da coleta dos dados. Os locais de reprocessamento sem exaustores expõem os profissionais aos vapores de glutaraldeído em suspensão no ar ambiente. Esse é um risco ocupacional frequente, durante o manuseio do glutaraldeído, principalmente se o uso do equipamento de proteção individual (luvas de nitrila, máscara com filtro químico, avental impermeável, óculos de proteção) for negligenciado, como observado por estudo ${ }^{(16)}$ realizado nas mesmas unidades de endoscopia.

Dados semelhantes, quanto à exposição ocupacional pela deficiência na aeração, na área de reprocessamento de artigos em glutaraldeído, foi observado por

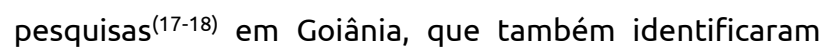
também a exposição dos profissionais ao produto e alto índice de sinais clínicos relacionados à atividade laboral.

A ausência de ponto com ar comprimido, constatada na maioria das unidades, compromete a etapa de secagem dos canais internos do endoscópio, em dois momentos: após a limpeza, deixando água no interior dos canais que contribui para a diluição do germicida químico utilizado para a desinfecção, com consequente queda na concentração e interferência no processo, e após a desinfecção que acontece ao final do reprocessamento. Vale ressaltar que a presença de umidade nos canais internos do endoscópio após o reprocessamento favorece a multiplicação de microrganismos, expondo a riscos os usuários submetidos ao exame. A RDC $n^{\circ} 50$ recomenda um ponto de ar comprimido medicinal por leito, nas salas de exames endoscópicos(3).

O uso de pia única com bancada é comum nas unidades de endoscopia, também é utilizada como superfície de apoio, durante todo o reprocessamento. Autores $^{(1)}$ indicam que além de bancadas, são necessárias quatro cubas, com tamanho e profundidades apropriadas para acondicionar o endoscópio, e que uma delas contenha tampa de acrílico para o germicida, fatores facilitadores para estabelecer o fluxo deste artigo.

O inox e o granito, materiais da maioria das bancadas, devido às suas características de durabilidade e alta resistência ao desgaste por abrasão, permite a limpeza e desinfecção como recomendadas(11).

O controle da temperatura ambiente das unidades de endoscopia é imprescindível para a manutenção preventiva dos equipamentos endoscópicos, sendo o ideal entre $20-23^{\circ} \mathrm{C}^{(1)}$. São essenciais aparelhos de ar condicionado nos serviços de endoscopia, pois a temperatura média anual, no Estado de Goiás, oscila em torno de 28 a $30^{\circ} \mathrm{C}$, segundo o Sistema de Meteorologia e Hidrologia do Estado de Goiás ${ }^{(19)}$. Vale ressaltar que os parâmetros de controle de temperatura e umidade relativa do ar estão comprometidos, devido à maioria $(68,4 \%)$ das unidades utilizarem ar condicionado do tipo janela. Estes aparelhos, segundo autores(20), não controlam esses importantes parâmetros e ainda, geram fluxo de ar turbulento e inadequado para os serviços de saúde.

É necessário o uso de ar condicionado, do tipo central, nas unidades de endoscopia, principalmente pela toxicidade e volatilidade do glutaraldeído. Outro ponto preocupante, que oferece risco à saúde do trabalhador, é a limpeza dos endoscópios realizada de 
forma manual, gerando aerossóis, implicando em risco biológico. O risco é potencializado, durante o reprocessamento do endoscópio, nas unidades de endoscopia, quando estes locais não apresentam exaustor, ar condicionado adequado e janelas. A RDC $n^{\circ}$ 50 recomenda que as instalações de ar condicionado em unidades médico-assistenciais devem proporcionar controle de temperatura, umidade relativa, fluxo unidirecional, grau de pureza do ar, porcentagem e volume de renovação do $\mathrm{ar}^{(3)}$.

Os dados mostram preocupação dos serviços com os locais de armazenamento dos endoscópios. A maioria armazena como o recomendado, isto é, em armários de fórmica, material de fácil limpeza, em temperatura ambiente, evitando umidade. Dos 15 (75,0\%) serviços que armazenavam os endoscópios em armários fechados, poucos $(35,0 \%)$ serviços continham a válvula de aeração nos armários que permite a ventilação interna, evitando calor excessivo. Entretanto, a utilização do suporte do aparelho endoscópico ou suporte de madeira fixado na parede não é recomendado devido à exposição direta do endoscópio ao ambiente, permitindo a contaminação. No entanto, foi utilizada em três $(15,0 \%)$ das unidades estudadas. Da mesma forma o uso da mala, observado como local de guarda em duas $(10,0 \%)$ das unidades de endoscopia, é contra-indicada pois seu material absorvente não pode ser desinfetado e a atmosfera no interior da mala fechada, potencialmente úmida, propicia o crescimento de microrganismos ${ }^{(1)}$.

Dentre todas as unidades de endoscopia participantes do estudo, apenas uma apresentou local específico para o reprocessamento do endoscópio. Isso despertou atenção e questionamento. Quais as barreiras enfrentadas pelas unidades que apresentam apenas uma sala de exame para atender os requisitos exigidos pela legislação quanto à estrutura física? Qual a percepção dos riscos químico e biológico dos responsáveis legais pelos serviços de endoscopia, que expõem os profissionais envolvidos neste contexto?

Estudos específicos, sobre estrutura física e área de reprocessamento, das unidades de endoscopias não foram encontrados para discussão dos achados do presente estudo. Contudo, documentos de sociedades de profissionais que trabalham com endoscopias e legislações existentes, no Brasil, apresentam as normas mínimas requeridas para a infra-estrutura necessária, a fim de que a qualidade da assistência e a segurança dos profissionais sejam garantidas ${ }^{(2-4)}$.

\section{CONCLUSÃO}

A maioria das unidades de endoscopia estudadas realizava o reprocessamento dos endoscópios no local de exame e o tamanho da área do local de exame e reprocessamento estão adequados. Entretanto, o fluxo era inadequado.

Dado predominante demonstra ainda a inobservância quanto às recomendações para o tipo de revestimento (piso e teto), local específico para higienização das mãos e vestiários para trabalhadores. Contudo, as unidades, em sua maioria, dispõem de local exclusivo para o armazenamento do endoscópio, sendo estes constituídos por armários fechados.

As deficiências estruturais, nos locais de reprocessamento, como: a ausência de exaustor, ponto com ar comprimido e local exclusivo para desprezar as secreções do frasco de aspiração, constituem em riscos químicos e biológicos aos trabalhadores, além de que podem comprometer o reprocessamento adequado do endoscópio. Em virtude do elevado número de variáveis, que interferem na qualidade, segurança e efetividade dos procedimentos assistenciais realizados nas unidades de endoscopia, é imprescindível o investimento em ações de planejamento da estrutura arquitetônica por parte dos gestores.

\section{REFERÊNCIAS}

1. Muller S, Lagemann RC. Enfermagem em Endoscopia Digestiva. 1th ed. São Paulo: MEDSI; 2002.

2. Ministério da Saúde; Agência Nacional de Vigilância Sanitária. Portaria $n^{\circ} 593$, de 25 de agosto de 2000. Aprova o Regulamento Técnico para Serviço de Endoscopia Digestiva e Respiratória. Brasília (Brasil): Ministério da Saúde; 2002.

3. Ministério da Saúde; Agência Nacional de Vigilância Sanitária. Resolução-RDC $n^{\circ}$ 50, de 21 de fevereiro de 2002. Regulamento técnico para planejamento, programação, elaboração de projetos físicos de estabelecimentos assistenciais de saúde. Brasília (Brasil): Ministério da Saúde; 2002.

4. Muller S, Graziano KU, Hoefel HHK. Manual de Reprocessamento de Limpeza e Desinfecção de Aparelhos e Acessórios Endoscópicos. Brasilia (Brasil): SOBEEG e ANVISA; 2006.

5. Sociedade Brasileira de Enfermeiros de Centro Cirúrgico, Recuperação Anestésica e Centro de Material e Esterilização (SOBECC). Práticas Recomendadas da SOBECC. 5th ed. São Paulo: SOBECC; 2009.

6. Padoveze MC, Graziano KU. Limpeza, desinfecção e esterilização de artigos em serviços de saúde. São Paulo: APECIH; 2010. 7. Society of Gastroenterology Nurses and Associates (SGNA). Standards of Infection Control in Reprocessing of Flexible Gastrointestinal Endoscopes. Chicago: SGNA; 2008. 
8. Alvarado CJ, Reichelderfer M. APIC Guideline for infection prevention and control in flexible endoscopy. Am J Infect Control. 2000;28(2):138-55.

9. Canadian society of gastroenterology nurses and associates (CSGNA). Infection Control - Recommended guidelines in the endoscopy setting. Canada: CSGNA; 2008.

10. Munhóz MM, Soares F. Arquitetura Hospitalar. In: Fernandes AT. Infecção Hospitalar e suas Interfaces na Área da Saúde. 1th ed. São Paulo: Atheneu; 2000. p. 290-2.

11. Ministério da Saúde. Processamento de Artigos e Superfícies em Estabelecimento de Saúde. Brasília (Brasil): Ministério da Saúde; 1994.

12. Carvalho PA. Temas de arquitetura de estabelecimentos assistenciais de saúde. 2 nd ed. Salvador: Faculdade de Arquitetura/UFBA; $2003.234 \mathrm{p}$.

13. Guadagnin SVT, Primo MGB, Tipple AFV, Souza ACS. Centro de Material e Esterilização: Padrões Arquitetônicos e o Reprocessamento de Artigos. Rev. Eletr. Enf. [Internet]. 2005 [cited 2010 nov 25];7(3):285-94. Available from:

http://www.fen.ufg.br/revista/revista7 3/v7n3.htm

14. Guadagnin SVT, Tipple AFV, Souza ACS. Avaliação Arquitetônica dos Centros de Material e Esterilização de Hospitais no Interior do Estado de Goiás. Rev. Eletr. Enf. [Internet]. 2007 [cited 2010 nov 25];9(3):656-73. Available from:

http://www.fen.ufg.br/revista/v9/n3/pdf/v9n3a07.pdf 15. Ministério da Saúde. Arquitetura na prevenção de infecção hospitalar. Saúde \& Tecnologia. Brasília (Brasil): Ministério da Saúde; 1995.

16. Neves HCC, Souza ACS, Barbosa JM, Ribeiro LCM, Tipple AFV, Alves SB et al. O Uso do Equipamento de Proteção Individual em Unidades de Endoscopia do Município de Goiânia. Rev. enferm. UERJ. 2010;18(1):61-6.

17. Tipple AFV, Souza ACS, Abreu NB, Domingues KK, Anders PS. O uso do glutaraldeído em serviços de saúde e a segurança do trabalhador. Rev. Enferm. UERJ. 2004;12(2):186-91.

18. Ribeiro LCM, Souza ACS, Barreto RASS, Barbosa JM, Tipple AFV Neves HCC et al. Risco ocupacional pela exposição ao glutaraldeído em trabalhadores de serviços de endoscopia. Rev. Eletr. Enf. [Internet]. 2009 [cited 2010 nov 25];11(3):509-17. Available from: http://www.fen.ufg.br/revista/v11/n3/pdf/v11n3a07.pdf

19. Secretaria de Ciência e Tecnologia do Estado de Goiás [Internet]. Brasília: SIMEGO (BR) [cited 2010 nov 25]. Sistema de Meteorologia e Hidrologia do Estado de Goiás Available from: http://www.simego.sectec.go.gov.br/clima/index.php 20. Afonso MSM, Souza ACS, Tipple AFV, Machado EA, Lucas EA. Condicionamento de ar em salas de operação e controle de infecção- uma revisão. Rev. Eletr. Enf. [Internet]. 2006 [cited 2012 mar 30];8(1):134-43. Available from:

http://www.fen.ufg.br/revista/revista8 1/revisao 01.htm.

Artigo recebido em 29.11.2010.

Aprovado para publicação em 26.01.2012.

Artigo publicado em 30.03.2012. 